\title{
Live microbial microbicides for HIV
}

\section{Dean Hamer*1, Louise McHugh ${ }^{1}$, Margaret McKinney ${ }^{1}$, Chris Richards ${ }^{1}$, Kevin Schully ${ }^{1}$, Laurel Lagenaur ${ }^{2}$ and Srinivas Rao $^{3}$}

\author{
Address: ${ }^{1}$ Laboratory of Biochemistry, National Cancer Institute, National Institutes of Health, Bethesda, Maryland, USA, ${ }^{2}$ Laboratory of Viral \\ Diseases, National Institute of Allergy and Infectious Diseases and Osel, Inc., Bethesda, Maryland, USA and 3Vaccine Research Center, National \\ Institutes of Health, Bethesda, Maryland, USA \\ * Corresponding author
}

from 2006 International Meeting of The Institute of Human Virology Baltimore, USA. 17-2I November, 2006

Published: 21 December 2006

Retrovirology 2006, 3(Suppl I):S50 doi:10.1I86/1742-4690-3-SI-S50

(c) 2006 Hamer et al; licensee BioMed Central Ltd.

\section{Background}

Most HIV transmission occurs on the mucosal surfaces of the gastrointestinal and cervico-vaginal tracts, which are coated by a biofilm of commensal bacteria. We are genetically engineering such naturally occurring bacteria to secrete peptides that block viral infection or replication. Introduction of such genetically modified organisms into uninfected individuals under conditions where they colonize the mucosa would provide a long lasting bioshield against HIV.

\section{Materials and methods}

Nissle 1917, a highly colonizing probiotic strain of E. coli, was genetically engineered to secrete an HIV fusion-blocking peptide through the hemolysin A secretion pathway. Lactobacillus jensenii 1153, a natural vaginal isolate, was modified to secrete the same peptide via the S-protein layer secretion pathway.

\section{Results}

By using a combination of cis- and trans-acting regulatory signals, micromolar secretion levels of the anti-HIV peptide were achieved in Nissle 1917. In vitro the genetically engineered E. coli potently blocked infection of T cells and macrophage by a wide spectrum of HIV primary isolates. In vivo, the modified strain colonized the lower intestine of rhesus macaques, and protected 50\% of animals against rectal infection by pathogenic SHIV162p3 in a small cohort of animals challenged shortly following colonization. Genetically engineered L. jensenii also secreted fusion-inhibitor peptide and colonized the vagina in estrus phase mice and in macaques.

\section{Conclusion}

Our data demonstrate the potential of genetically modified commensal bacteria to provide cheap, effective protection against HIV infection. 